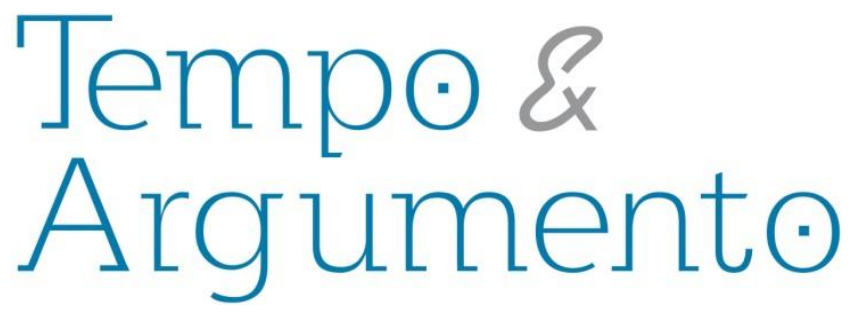

\title{
A experiência dos séculos XX e XXI nos projetos pedagógicos dos cursos de graduação em história no Brasil (2003-2014) ${ }^{1}$
}

\begin{abstract}
Resumo
Neste texto, tomamos, operatoriamente, a noção de presente como experiência circunscrita aos séculos $X X$ e $\mathrm{XXI}$ e examinamos as prescrições disponíveis nos projetos pedagógicos dos cursos de formação inicial em história em 54 instituições brasileiras, distribuídas em todos os estados da federação. Com ele, descrevemos e comentamos 0 perfil idealizado das habilidades profissionais, a distribuição da carga horária entre os saberes a ensinar e os saberes teóricos e da prática educacional, o lugar e a natureza da experiência do presente nas ementas das disciplinas acadêmicas. A proximidade do lançamento da última versão da Base Nacional Curricular Comum e as reformas que esse documento e sua implicação nos cursos de licenciatura em história, ainda em 2017, são as principais motivações para a divulgação desta empreitada.
\end{abstract}

Palavras-chave: Estudo Ensino (Superior) - Brasil. Professores de História - Formação. Historiadores Formação.

\author{
Itamar Freitas \\ Doutor em Educação pela Pontifícia \\ Universidade Católica de São Paulo (PUC/SP). \\ Doutorando em História Universidade Federal \\ do Rio Grande do Sul (UFRGS). Professor do \\ Mestrado Profissional em Ensino de História \\ História e do Programa de Pós-Graduação em \\ Educação da Universidade Federal de Sergipe \\ (UFS). \\ São Cristóvão, Sergipe - BRASIL \\ itamarfreitasufs@gmail.com
}

\section{Para citar este artigo:}

FREITAS, Itamar. A experiência dos séculos XX e XXI nos projetos pedagógicos dos cursos de graduação em história no Brasil (2003-2014). Tempo e Argumento, Florianópolis, v. 9, n. 22, p. 396 428, set./dez. 2017.

\author{
DOI: $10.5965 / 2175180309222017396$ \\ http://dx.doi.org/10.5965/2175180309222017396
}

\footnotetext{
${ }^{1}$ Este texto é parte dos resultados de uma Pesquisa financiada pela Coordenação de Aperfeiçoamento de Pessoal de Nível Superior (CAPES), dentro do Programa Nacional de Pós-Doutorado (PNPD), sob a supervisão do Prof. Dr. Arthur Assis Alfaix, entre janeiro e dezembro de 2014, no Programa de PósGraduação em História da Universidade de Brasília (PPGHIS/UNb).
} 


\title{
The experiences of the 20th and 21st centuries in the pedagogical projects for undergraduate programs in history in Brazil (2003-2014)
}

\begin{abstract}
In this text, we assume the notion of present as an experience circumscribed to the 20th and 21st centuries and examine the available prescriptions of the pedagogical projects for undergraduate programs in history from 54 Brazilian institutions, distributed in all the states of the federation. Thus, we describe and comment the idealized skilss of professional profiles, the distribution of the relationship between the know how to teach and the theoretical knowledge and the educational practice, the place and nature of the knowledge of present in the menus for the academic disciplines. The proximity between the latest version of the Common National Base and the reforms that this document will imply in undergraduate programs in history, demonstrated until 2017, are the main motivations for this research.
\end{abstract}

Keywords: Undergraduate In History. Present. XX and XXI Centuries.

Já se disse à exaustão que "Historia del tempo presente", "tiemps présent", "histoire proche", "contemporary history", "history of our own time", "Zeitgeschicht", "neuste Geschichte" e "nueste Zeitgeschichte" são variantes que designam - em países de língua espanhola, francesa, inglesa e alemã - uma disciplina acadêmica, subdisciplina, campo, enfoque ou categoria para a análise da experiência humana (ROUSSO, 2013; PALMOWSKI y READMAN, 2011; BERNECKER, 1998). 
Embora a maioria dos especialistas discorde da redução dos limites desses objetos a um lapso cronológico, ainda não conseguiram se desvencilhar da necessidade de estabeler um "agora" humano (KOSSELECK, 2006), apontando início e fim da experiência narrada, tão a gosto das sábias demarcações de Santo Agostinho (1964) em suas aporias sobre o tempo. Em outros termos, mesmo tratando o objeto como o "vivido" do historiador ou, em modos mais sofisticados, como uma "catástrofe", singular à determinado povo, situável em escalas temporais móveis e também singulares (ROUSSO, 2012; 2013) - o extermínio dos judeus para a Alemanha, o franquismo para a Espanha, o colaboracionismo de Vichy para a França, a ditadura de Pinochet para o Chile, o massacre de Nanquin para o Japão e, em proporções, evidentemente, muito menores, o massacre do Carandiru para o Brasil, entre outros ${ }^{2}-$, historiadores conservam o a priori kanteano do tempo cronológico na representação/realização das suas "coisas" de estudo. E mais: apesar de questionarem as teleologias frequentes nos trabalhos de síntese histórica, sobretudo aquelas que ganham forçarou entre os séculos XVIII e XIX, de sugerirem os jogos de durações ao gosto de Fernand Braudel (2004), a maioria dos historiadores não consegue situar os seus "passados que não passam", "memórias que desafiam a história", "incômodas feridas" que teimam em não cicatrizar etc. longe das balizas do século XX e do nosso século XXI.

Por esse raciocínio, a experiência dos séculos XX e XXI, se não é suficiente para constituir "o presente", não pode ser extirpada das tentativas de definição de "um tempo presente". Séculos XX e XXI são “presente”, é lógico, de modo típico ideal. Mas o são com grandes vantagens sobre as demais delimitações, quando se quer empreender uma descrição e estabelecer marcos para eventuais histórias comparadas sobre a formação dos historiadores. A discussão sobre essa particular experiência é oportuna, principalmente no contexto das recentes iniciativas de mudança curricular no ensino de história para os níveis fundamental e superior. Entre 2015 e 2016, vivenciamos debates acirrados acerca das duas primeiras versões da Base Nacional Curricular Comum, instrumento normativo elaborado pelo Ministério da Educação, que cumpre atribuições

\footnotetext{
2 Excetuando-se a experiência narrada recentemente, que trata do Carandiru (BORGES, 2016), as demais são flagradas em referências cruzadas entre autores clássicos (CHAVEAU e TÉTARD, 1999; ARÓSTEGUI, 2004; PORTO JÚNIOR, 2007; DOSSE, 2007; VARELA et. al, 2012; SILVA, 2012 e HARTOG, 2012).
} 
demandadas pelo Plano Nacional de Educação (2015). A BNCC estabelece parâmetros mínimos para a seleção de conteúdo (substantitivo, valorativo e procedimental) que formatará os programas, livros didáticos e avaliações por escala, a partir de 2017, e foi alvo de discussão sobre os conteúdos mínimos a serem normatizado pelo Estado. Para o ensino superior, a discussão se concentrará na consequente reforma das licenciaturas que deverá contemplar o novo conteúdo estabelecido pela BNCC. O processo de reforma aguarda a sanção ministerial da BNCC que ainda tramita no Conselho Nacional de Educação.

Frente às recentes disputas sobre as experiências datáveis que se devem tornar obrigatórias, tanto na BNCC quanto nos projetos pedagógicos dos cursos de licenciatura em história, pensamos que uma reflexão sobre o conteúdo substantivo encarnado nesses dois algarismos romanos pode nos auxiliar bastante na avaliação da natureza e do lugar da experiência recente nas prescrições sobre formação inicial dos professores de história3.

Neste artigo, problematizamos os diferentes sentidos de presente atribuídos, justificados, historiados e prescritos como conteúdos para as disciplinas acadêmicas qualificadas como "de história" ou "história de", em diferentes estados brasileiros. Com ele, rememoramos e, em alguns pontos, aprofundamos discussões relativas aos usos públicos da história, às distinções entre passado e presente operadas por várias culturas e historiografias (BEVERNAGE; LORENZ, 2013) e às conexões entre política e história, Estado e produção do conhecimento histórico (MARTINS, 2006). Aqui, exploramos os sentidos de presente no mundo acadêmico, especificamente nas prescrições anunciadas pelos projetos pedagógicos dos cursos de graduação em história classificadas como

\footnotetext{
3 Não obstante a qualificada produção sobre as relações entre ensino de história e história do tempo presente, não encontramos investigação similar que nos permitisse estabelecer diálogos mais frutíferos em torno do lugar da experiência dos séculos XX e XXI na formação inicial do ensino de história. Buscamos, principalmente, os raros textos que historiam a formação do campo no Brasil (BERETA, 2006; SILVA, 2012), dossiês sobre ensino de história (2009-2014), a totalidade dos números das revistas especializadas (Tempo e Argumento, História Agora, Cadernos do Tempo Presente e Tempo presente, no período 2006-2014) e o dossiê da Revista História Hoje (v. 2, n. 4, 2013), intitulado "O ensino de história e o tempo presente". Contudo, dois textos merecem destaque por focarem, respectivamente, experiência recente dos currículos do ensino superior de história no Brasil em termos de prática de ensino de história e relação ensino-pesquisa. Trata-se do artigo de Flávia Caimi (2013) e da tese de doutorado de Ângela Ribeiro (2015).
} 
Tentando viabilizar essas intenções, construímos o texto a partir de cinco questões: quais as habilidades que o futuro profissional de história deve dominar? Como os projetos pedagógicos distribuem a carga horária dos cursos de forma a equilibrar os "saberes a ensinar", "saberes da prática de ensinar" e "saberes teóricos da história e da educação"? Qual o espaço ocupado pelo presente nas disciplinas relativas aos "saberes a ensinar"? Qual a natureza do presente disseminada por esses currículos, no que diz respeito à periodização e à acontecimentalidade?

\section{Os saberes ideais}

O projeto pedagógico (PP) é o documento básico para a instituição de curso de graduação em história. Pode não ser lido ou praticado, mas tem que ser produzido e, de certa forma, discutido e defendido. ${ }^{4}$ Algo tem que ser posto no papel que justifique, inclusive, a obtenção de recursos para as instalações, a contratação de professores e, é claro, a abertura de vagas nos cursos superiores. Dele, nos interessam, portanto, o conteúdo a ensinar, em especial o que prescreve a experiência do presente. Mas, é importante também saber o que dizem esses dispositivos acerca das finalidades do curso.

\footnotetext{
4 O Projeto Pedagógico de um curso de licenciatura em história no Brasil é constituído a partir de prescrições internas à instituição que oferta o curso e também com base nas normas para a criação de cursos superiores disseminadas por pareceres e resoluções emitidos pelo Conselho Nacional de Educação que, por sua vez, dá conta de legislação prescritora de conteúdo substantivo em diferentes políticas públicas, como a defesa do meio ambiente, a educação pelos direitos humanos e a inclusão da experiência de povos indígenas e população afro-brasileira. Hoje, o principal documento que estabelece os elementos básicos de um Projeto Pedagógico são as "Diretrizes Curriculares para os cursos de História", que assim orientam: "O projeto pedagógico de formação acadêmica e profissional a ser oferecido pelo curso de História deverá explicitar: a) o perfil dos formandos nas modalidades bacharelado e licenciatura; b) as competências e habilidades - gerais e específicas a serem desenvolvidas; c) as competências e habilidades específicas a serem desenvolvidas na licenciatura d) a estrutura do curso, bem como os critérios para o estabelecimento de disciplinas obrigatórias e optativas do bacharelado e da licenciatura; e) os conteúdos curriculares básicos e conteúdos complementares; f) o formato dos estágios; g) as características das atividades complementares; $h$ ) as formas de avaliação." (Art. $1^{\circ}$ da Resolução CNE/CES, n. 13, de 13 de março de 2002, que estabelece as Diretrizes Curriculares para os cursos de História).
} 
Quanto a esse ponto, em geral, habilidades historiadoras, ${ }^{5}$ habilidades da prática de ensino e os valores estão presentes nos documentos ${ }^{6}$. Considerados os usos desses elementos, entretanto, percebemos que metade das instituições aqui analisadas privilegia as habilidades da pesquisa e da escrita da história, seja de modo direto “coletar, processar informações, entender e analisar as fontes de forma crítica e dominar os procedimentos de formulação de projetos e produção de pesquisa" (UFSC) -, seja de modo genérico - “conhecer as principais vertentes teóricas que orientam as análises históricas" (UFG).

O grupo de instituições em que predominam as habilidades da teoria e prática de ensino representa, aproximadamente, $17 \%$. Nele, podem ser flagradas desde as finalidades relativas ao domínio de técnicas de avaliação e planejamento, teorias da aprendizagem até o politicamente incorreto (embora, logicamente necessário) “domínio dos conteúdos" ensináveis nos anos finais do ensino fundamental e do ensino médio (UFPR). Nesse quesito, também encontramos extremos e equilíbrios. A UFAL, por exemplo, reserva $82 \%$ das habilidades reveladoras do perfil do egresso ao domínio dos saberes da prática, enquanto a UFC nada reserva à questão. A UFRN e a UFT são casos em

\footnotetext{
${ }^{5}$ Consideradas as diferentes fundamentações contemporâneas sobre identidade profissional do historiador (formação incial e pós-graduada em história, assalariamento, ou ainda, a atividade de ensino de história em tempo integral), a rigor, não há um valor, um procedimento motor ou um princípio aplicado (habilidades) inerente ao trabalho do historiador. Todos eles estão presentes, em número e intensidades diferentes, no trabalho de profissionais de outros campos como a Sociologia, Geografia, Linguística, Filosofia. Os programas de formação inicial em história, os manuais de introdução à história e de teoria da história e os corpos editoriais de revistas científicas, contudo, por razões que vão da necessidade de fixar um ethos e até mesmo a permanência de determinados procedimentos de pesquisa ao longo de um século e meio (na Europa, Ásia e América, sobretudo), depositam tal identidade no emprego de habilidades típicas dos casos exemplares de historicistas alemães e, em menor caso, franceses, que viveram entre metade do século XIX e metade do XX: a transparência na relação com o leitor (em termos de perspectiva interpretativa e de natureza das fontes), a necessidade de argumentar apenas apoiado em evidências. Esses axiomas são potencialmente garantidos a partir das operações de heurística, crítica, interpretação e composição. É esse conjunto de "habilidades" que veremos adiante na descrição dos Projetos Pedagógicos.

${ }^{6}$ Para fornecer um perfil dos conteúdos ensináveis na licenciatura em história, coletamos e analisamos os programas de 55 cursos ofertados em instituições de todas as unidades da federação, significando, portanto, $20 \%$ do total (aproximadamente, seis centenas) de cursos registrados no Ministério da Educação no ano de 2014. Selecionamos, no mínimo, um curso aberto por uma universidade pública, federal ou estadual e, quando possível, confessional para cada estado. Os projetos político-pedagógicos foram submetidos à análise estatística e qualitativa do discurso (Guiraud, 1960). As disciplinas, como veremos adiante, foram tipificadas segundo as categorias estabelecidas e submetidas à classificação de Pascal Guibert e Vincent Troger (2012, p. 129-130): "saberes a ensinar", "saberes teóricos da ciência" (subdivididos em ciência da história e ciência da educação), e "saberes da prática de ensino".
} 
que há equidade entre saberes teóricos da história e saberes teóricos da prática de ensino. A maioria, contudo, embora em doses bem modestas, faz referências aos valores, relacionando a ação do historiador à formação cidadã - no sentido de respeito à diversidade e/ou formação do pensamento crítico (UFMT, UFU, UFRGS, entre outras). É provável que a ênfase nas temáticas da "prática de ensino" esteja relacionada à forte presença dos profissionais da Pedagogia na construção da legislação estatal que orienta a abertura de cursos de graduação. Outra hipótese também a ser considerada é o fato de os cursos de graduação funcionarem, na maioria dos estados brasileiros, desacompanhados de programas de Pós-Graduação em História, radicados, principalmente, em instituições privadas.

Esse breve balanço sobre os perfis dos imaginados egressos anunciados pelos PPcs, entretanto, não serve como parâmetro para os cruzamentos que efetuamos adiante, acerca do conteúdo anunciado nas ementas, já que nem todos os documentos obtidos permitem o levantamento das habilidades formadoras do profissional ideal?. Contudo, podem matizar um pouco a ideia de que as diretrizes estabelecidas pelo Ministério da Educação - MEC engessam os projetos pedagógicos - ao menos em termos de finalidades do curso de graduação de história. Vejamos agora o que efetivamente pode revelar esse tipo de fonte sobre o lugar dos saberes a ensinar e a situação do presente como conteúdo da formação inicial.

\section{Cursos de formação inicial: um perfil da distribuição da carga horária}

No Brasil de 2014, limitados à amostra de aproximadamente $20 \%$ dos cursos de graduação em história ofertados, constatamos que a carga horária total reservava 39\% das horas para os "saberes a ensinar"8. A segunda maior fatia do tempo, 24\%, foi atribuída

\footnotetext{
7 Essa quantificação foi produzida a partir do exame dos projetos pedagógicos das seguintes instituições: UFAL, UFC, UFCG, UFES, UFFS, UFG, UFMG, UFMT, UFOP, UFPA, UFPR, UFRGS, UFRN, UFRR, UFS, UFSC, UFSJ, UFT, UFTM, UFU, UFVJM, UNIFAP, URCA, URFB.

${ }^{8}$ Conteúdos disciplinares universitários transformados em conteúdos disciplinares para a escola, sobretudo acontecimentais: histórias da África, afro-brasileira, afro-brasileira/indígena, América, antiga, antiga/filosofia, antiga/medieval, Ásia, Ásia/África, Brasil, Brasil/África, Brasil-contemporâneo, contemporânea, ibérica, indígena, local/regional, medieval, moderna, moderna/contemporânea, Oriente, Portugal, pré-história, pré-história/arqueologia, tempo presente.
} 
aos "saberes teóricos da ciência da história"9. Os dois últimos lotes são reservados aos “saberes da prática de ensino"10 (16\%) e aos "saberes teóricos da educação" (15\%).

Evidentemente, a distribuição não é homogênea entre os $\operatorname{cursos}^{12}$, mas conserva a relativa semelhança na distribuição da carga horária por disciplina, dentro das classes privilegiadas por este estudo. Para os saberes a ensinar, 45 das 59 instituições reservaram entre 60 e 80 horas por disciplina. O mesmo espaço (entre 6oh e 80 h) ocupado pelos saberes teóricos da ciência da história e os saberes teóricos do ensino de história estão presentes em, respectivamente, 44 e 37 instituições. A grande variação fica mesmo por conta dos saberes da prática. Por fim, 16 instituições concederam, em média, até 100 horas por disciplina, 30 reservaram entre 100 e 200 horas e 13, mais de 200 horas.

Para o que nos interessa, diretamente, neste texto, é forçoso registrar que a experiência do presente frequenta as quatro classes aqui citadas. No entanto, é comum e mais intensamente discutida na classe primeira - saberes a ensinar - que ocupa $39 \%$ da carga horária total identificada nos currículos e, em média, idênticos 39\% da carga horária total do currículo de cada instituição. Esse espaço é preenchido com pouco mais de duas dezenas de disciplinas que selecionam seu conteúdo a partir de critérios que orientavam a instituição de cadeiras, cursos e seminários, desde meados do século XVIII, na

\footnotetext{
${ }^{9}$ Além da Introdução à História, incluem, na maioria dos casos e em caráter propedêutico: antropologia, arqueologia, arquivologia, arte, ciência/técnica, ciências sociais, cultura, história cultural, economia, economia/política, epistemologia, estatística, filosofia, geografia, geo-história, gestão cultural, historiografia, literatura/mídia, lógica/linguagem/comunicação, lugares de memória/ensino de história, matemática, memória/arquivo, memória/patrimônio, metodologia científica, metodologia da história, monografia, museologia, museu/galeria/monumento, patrimônio, política, política/economia, relações internacionais, sociologia, sociologia/antropologia, teoria, teoria/historiografia, teoria/metodologia da história, teoria/metodologia da história/historiografia.

${ }^{10}$ As clássicas disciplinas de Estágio Supervisionado e a própria Prática de Ensino.

${ }^{11}$ Representado pelas disciplinas avaliação, currículo, currículo/didática/planejamento, currículo/gestão, currículo/política/gestão, didática, educação, educação e comunicação/novas tecnologias da informação e da comunicação, educação e sociologia, educação de jovens e adultos, estatística aplicada à educação, filosofia da educação, história da educação, inclusão, metodologia da pesquisa, ensino de geografia, estrutura e funcionamento do ensino, gestão, metodologia do ensino de história, metodologia do ensino de geografia, metodologia do ensino de história/novas tecnologias da informação e da comunicação, metodologia do ensino, organização do trabalho pedagógico, libras, planejamento, avaliação e psicologia.

${ }^{12}$ Isso se deve, entre outros fatores, à ausência de designação das disciplinas (entre $10 \%$ e $38 \%$ em 12 universidades), ausência de informação sobre a carga horária (uma instituição), não designação das disciplinas relativas aos "saberes da prática docente" e aos "saberes teóricos do ensino de história", fruto da variedade de modelos de oferta do curso: bacharelados, licenciaturas e bacharelados integrados às licenciaturas ou, ainda, oferta independente dos saberes da prática e dos teóricos da educação (nos departamentos de história) ou partilhada com os centros, faculdades ou departamentos de educação.
} 
Alemanha, e primeira metade do século XIX, na França. Tais critérios, que também ordenavam a disposição do conteúdo histórico substantivo nas narrativas veiculadas pelos impressos propedêuticos ao ensino de história nos cursos secundários e superiores eram chamados de "método etnográfico", "método cronológico" e "método geográfico". Este último ${ }^{13}$ - que privilegia o recorte espacial - predomina em 49 das 59 instituições, fornecendo a base para a designação das disciplinas mediante diferentes escalas: transnacional (História da América, da África, Ásia [Oriente]?), nacional (Brasil e Portugal) e regional/local (História da Paraíba, do Nordeste, da Fronteira Sul ou da Amazônia, entre outros).

O segundo critério, dominante em apenas quatro instituições ${ }^{14}$, tem a diacronia estabelecida por fundamento, mantendo uma prática instituída nos cursos secundários (alemães, franceses e ingleses), entre os séculos XII e XVIII, de recortar a história do mundo em períodos correlatos à idade de uma pessoa: infância, maturidade e velhice, ou seja, história Antiga, Medieval e Moderna15. Nas instituições superiores brasileiras, além dessas três rubricas, fazem parte do currículo a Pré-História, História Contemporânea e a História do Tempo Presente. Em equilíbrio, estão sete instituições que nomeiam 50\% das disciplinas a partir do recorte temporal e também 50\% a partir do recorte espacial. Por fim, há disciplinas que são nomeadas a partir de critérios étnico-culturais (História Indígena e História da Cultura Afro-Brasileira) ou acontecimentais (História das Revoluções). Ainda assim, esse critério não é majoritário em nenhuma instituição que anuncia tais disciplinas. ${ }^{16}$

Por experiência própria, entretanto, sabemos todos que os critérios são intercambiáveis. Assim, a disciplina, cujo espaço ganha relevo no título, é também entrecortada por períodos, dando origens às conhecidas histórias do Brasil Contemporâneo, Brasil Monárquico, América Colonial, América Independente ou, simplesmente, Brasil II e América I - que também indicam lapsos de tempo. Com isso,

\footnotetext{
13 Sobre a relação entre cursos de história e modos de regrar a escrita da história na França e na Alemanha desse período, ver, sobretudo, Charles-Olivier Carbonell (1976).

14 UEMS, UFMS, UFRGS e UnB.

15 Exemplos desses conflitos estão em F. G. Rühs (1811). Uma síntese das periodizações clássicas foi elaborada por José Honório Rodrigues (1969), no clássico Teoria da História do Brasil.

${ }^{16}$ UEMS, UERR, UFFS, UFMS, UFOPA, UFPA, UFPI, UFS, UFSM e UNIFAP.
} 
queremos, mais uma vez, alertar que o tempo presente buscado por nós pode estar inserido nas três classes de saberes que constituem o currículo e, ainda, nas disciplinas designadas pelos mais diferentes critérios aqui listados. Assim, a experiência dos séculos XX e XXI é matéria de grande parte das disciplinas dos cursos de graduação em história no Brasil.

A Tabela 1 apresenta uma síntese da distribuição da carga horária total de cada grupo de disciplinas da rubrica "saberes a ensinar" de 44 instituições ${ }^{17}$, de 25 estados ${ }^{18}$. Observem que o nosso tempo presente configura os conteúdos de nove das 22 disciplinas, isto é, $41 \%$ das disciplinas desse tipo incorporam o tempo presente como conteúdo.

Tabela 1 - Distribuição do tempo segundo as disciplinas da rubrica "conteúdos a ensinar", em instituições brasileiras que ofertam o curso de licenciatura em História.

\begin{tabular}{|c|c|c|c|c|c|c|c|c|c|c|c|}
\hline Tempo inicial & BB* & $M^{*}$ & VaC. & v & $X V$ & XIX & $\mathrm{XIX}$ & $x X$ & $X X$ & \multirow{2}{*}{ NC } & \multirow{2}{*}{ Total } \\
\hline Tempo final & IV & $\mathrm{XX}$ & $\mathbf{v}$ & $\mathrm{XV}$ & XIX & XIX & $\mathrm{XX}$ & $x X$ & XXI & & \\
\hline \multicolumn{12}{|l|}{ Disciplinas } \\
\hline África $^{1}$ & & $35 \%$ & & & $19 \%$ & $3 \%$ & $6 \%$ & $3 \%$ & & $32 \%$ & $100 \%$ \\
\hline Afro-brasileira & & & & & $20 \%$ & & & & & $80 \%$ & $100 \%$ \\
\hline América $^{2}$ & & $19 \%$ & & $1 \%$ & $31 \%$ & $9 \%$ & $20 \%$ & $10 \%$ & $4 \%$ & $6 \%$ & $100 \%$ \\
\hline Antiga $^{3}$ & $13 \%$ & $36 \%$ & $43 \%$ & $5 \%$ & & & & & & $4 \%$ & $100 \%$ \\
\hline Antiga/Filosofia & & & $100 \%$ & & & & & & & & $100 \%$ \\
\hline Antiga/Medieval & & & $100 \%$ & & & & & & & & $100 \%$ \\
\hline Ásia & & & & & & & $100 \%$ & & & & $100 \%$ \\
\hline Ásia/África & & & & & & & & $100 \%$ & & & $100 \%$ \\
\hline
\end{tabular}

17 IFG (GO), PUC (RJ, RGS, Campinas-SP), UDESC (SC), UEMS (MS), UERJ (RJ), UERN (RN), UESC (BA), UFAC (AC), UFAL (AL), UFAM (AM), UFC (CE), UFCG (PB), UFES (ES), UFFS (SC), UFG (GO), UFJF (MG), UFMA (MA), UFMG (MG), UFMT (MT), UFOPA (PA), UFPA (PA), UFPE (PE), UFPEL (RS), UFPI (PI), UFRJ (RJ), UFRN (RN), UFRR (RR), UFS (SE), UFSC (SC), UFSJ (MG), UFT (TO), UFTM (MG), UFU (MG), UFVJM (MG), UNEAL (AL), Unicamp (SP), UNIFAL (MG), UNIFAP (AP), UNIFESP (SP), UNIR (RO), URCA (CE) e USP (SP).

${ }^{18} \mathrm{AC}, \mathrm{AL}, \mathrm{AM}, \mathrm{AP}, \mathrm{BA}, \mathrm{CE}, \mathrm{ES}, \mathrm{GO}, \mathrm{MA}, \mathrm{MG}, \mathrm{MS}, \mathrm{MT}, \mathrm{PA}, \mathrm{PB}, \mathrm{PE}, \mathrm{PI}, \mathrm{RJ}, \mathrm{RN}, \mathrm{RO}, \mathrm{RR}, \mathrm{RS}, \mathrm{SC}, \mathrm{SE}, \mathrm{SP}$ e TO. Lembremos, novamente, que nem todos os documentos recolhidos fornecem o ementário. 


\begin{tabular}{|c|c|c|c|c|c|c|c|c|c|c|c|}
\hline Brasil & & & & & $25 \%$ & $22 \%$ & $7 \%$ & $34 \%$ & $7 \%$ & $3 \%$ & $100 \%$ \\
\hline Brasil/África & & & & & $100 \%$ & & & & & & $100 \%$ \\
\hline Contemporânea & & & & & $12 \%$ & $15 \%$ & $20 \%$ & $40 \%$ & $8 \%$ & $5 \%$ & $100 \%$ \\
\hline Ibérica & & & & & $33 \%$ & & $33 \%$ & & & $33 \%$ & $100 \%$ \\
\hline Indígena 4 & & $17 \%$ & & & & & & & & $83 \%$ & $100 \%$ \\
\hline Local/Regional5 & & $5 \%$ & & & $19 \%$ & $5 \%$ & $17 \%$ & $11 \%$ & $8 \%$ & $35 \%$ & $100 \%$ \\
\hline Medieval & & & & $100 \%$ & & & & & & & $100 \%$ \\
\hline Moderna & & & & & $97 \%$ & & & & & $3 \%$ & $100 \%$ \\
\hline Oriente $^{6}$ & & $100 \%$ & & & & & & & & & $100 \%$ \\
\hline Portugal & & & & & & & & & & $100 \%$ & $100 \%$ \\
\hline Pré-história7 & $90 \%$ & $10 \%$ & & & & & & & & & $100 \%$ \\
\hline Pré-história/Arq. $^{8}$ & $100 \%$ & & & & & & & & & & $100 \%$ \\
\hline Revoluções & & & & & & & & & & $100 \%$ & $100 \%$ \\
\hline Tempo Presente & & & & & & & & $100 \%$ & & & $100 \%$ \\
\hline Total & $2 \%$ & $8 \%$ & $4 \%$ & $9 \%$ & $25 \%$ & $10 \%$ & $10 \%$ & $17 \%$ & $4 \%$ & $9 \%$ & $100 \%$ \\
\hline
\end{tabular}

Obs.: (1) Com limites entre 10.000 a.C. e o século XX. (2) 1\% das disciplinas com limites entre 10.000 a.C. e $18 \%$ com limites entre 10.000 a.C. e século XX. (3) $13 \%$ das disciplinas com limites entre 2.000 .000 .000 a.C. e século IV, $34 \%$ entre 10.000 a.C. e século IV e $2 \%$ com limites entre 10.000 a.C. e o século XX. (4) Com limites entre 10.000 a.C. e o século XX. (5) Com limites entre 10.000 a.C. e o século XX. (6) Com limites entre 10.000 a.C. e o século XX. (7) $80 \%$ das disciplinas com limites entre 2.000 .000 .000 e 10.000 a.C., $10 \%$ entre 2.000 .000 .000 e o século IV e também $10 \%$ com limites entre 10.000 a.C. e o século IV. (8) Com limites entre 2.000 .000 .000 e 10.000 a.C.

(*) $\underline{B B}$ - Dois bilhões de anos antes de Cristo; $\underline{M}$ - Um milhão de anos antes de Cristo.

A existência do tempo presente, contudo, vai sendo matizada na medida em que refinamos as questões. Vamos à primeira: qual o espaço reservado no grupo de cada disciplina para os séculos XX e XXI? O Gráfico 1 evidencia que as disciplinas História do Tempo Presente e História da Ásia, Ásia/África e da África são destinadas, exclusivamente, a esse período (100\%), seguidas pelas histórias contemporânea (58\%), da Ásia (50\%) e do Brasil (45\%). É importante alertar sobre uma provável leitura equivocada da situação da HTP nos cursos brasileiros a partir desses números. Os espaços ocupados por essas disciplinas, no total de horas de cada caso e no conjunto de todas as instituições 
exemplo, da história da Ásia. Pesam pouco os $50 \%$ reservados à HTP no conjunto doscursos de história da UNIFESP e da PUC-RS, únicas instituições que a incorporam na matriz curricular.

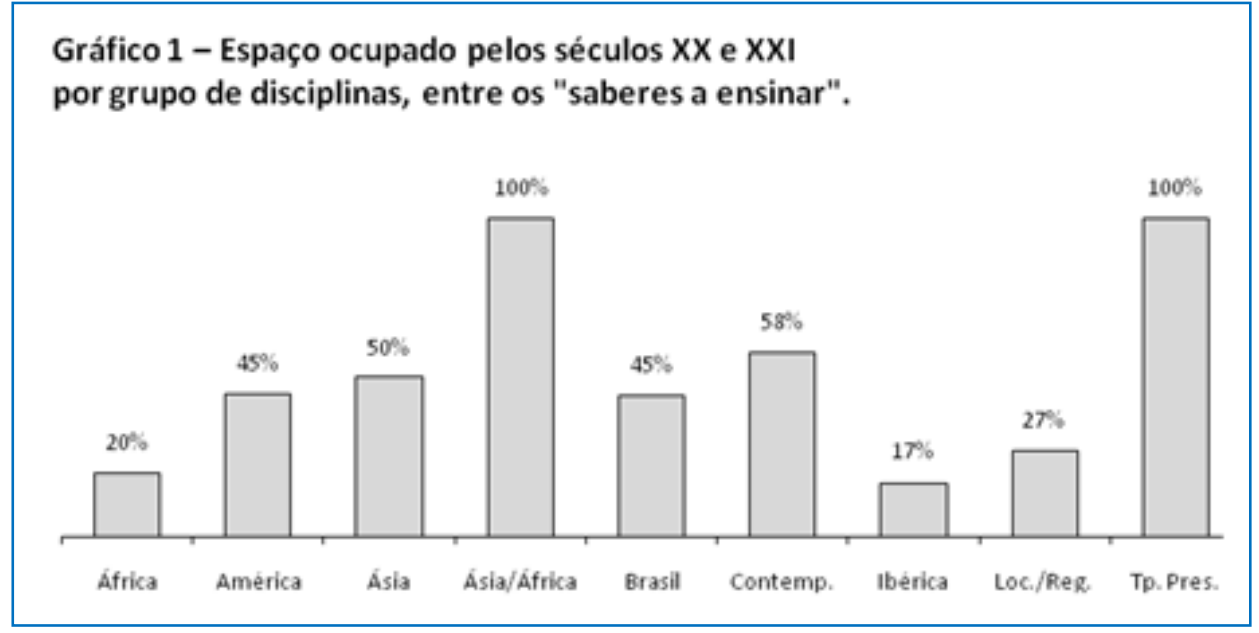

Isso nos obriga, então, a problematizar a representatividade dessas disciplinas em cada projeto pedagógico e no cômputo geral dos cursos examinados quando a rubrica, lembramos, são os saberes a ensinar. Se observarmos a distribuição da carga horária ofertada pelo conjunto das instituições, perceberemos onde mais se investe no Brasil, em termos de contratação de professores e, talvez, na pesquisa histórica - limitados, evidentemente, à nossa amostra -, em termos de saberes a ensinar: a história do Brasil, ocupando $27,5 \%$, apresenta-se como disciplina de alta frequência nos cursos de história. As histórias da América (15,7\%), contemporânea (12,6\%), moderna (9,3\%), local/regional (9,2\%) e antiga (8,7\%) representam as médias frequências. As histórias da África (4,5\%), pré-história (1,4\%) e a história indígena (1\%), por fim, apesar de terem recebido aportes em termos de vagas, desde meados da década passada, são disciplinas de baixa frequência. As demais são desprezíveis, quantitativamente, não chegando a 1\% da carga horária total alocada. 
No currículo de cada instituição, percebemos algumas semelhanças e radicais diferenças na distribuição, a começar pela presença ou pela ausência de determinadas disciplinas. Fiquemos apenas com esses exemplos, para concluirmos o tópico com o lugar do contemporâneo nos cursos de licenciatura. A história moderna é bastante homogênea. Considerando 50\% dos cursos como ponto de corte (22 instituições), veremos que ela ocupa entre 14\% e 10\% do número de disciplinas. Com as histórias contemporânea e da América, a situação se inverte. Nesses mesmos 50\% de cursos, a variação fica entre $21 \%$ e $13 \%$ para a primeira e entre $31 \%$ e $15 \%$ para a segunda. Caso extremo de diferença é a história da África. Na UDESC, por exemplo, ela ocupa $11 \%$ dos saberes a ensinar, enquanto na UFMT, esse número cai para modestos 3\%.

Essa breve digressão foi empregada apenas para matizarmos as informações relativas ao lugar dos séculos $\mathrm{XX}$ e $\mathrm{XXI}$ entre os saberes a ensinar. Ponderadas as semelhanças e diferenças, como também os variados pesos das disciplinas no total da carga horária alocada por cada instituição e no total das instituições, chegamos a essa imagem mais realista (Gráfico 3) 19: o tempo presente é mais frequente nas histórias do Brasil (11\% da carga horária das disciplinas assim designadas) e contemporânea (7,34\%) e medianamente frequente nas disciplinas nomeadas como história da América (3,76\%) e local/regional (2,53\%). As anteriores referidas, África (0,27\%), Ásia (0,15\%), Ásia/África (0,20\%), Ibérica $(0,27 \%)$ e tempo presente são desprezíveis no cômputo geral.

\footnotetext{
19 Para compreender como chegamos a este resultado, considerem que os números relativos referem-se ao número de disciplinas e à classe temporal (XV-XIX, XIX, XX-XXI etc.) à qual cada ementa de disciplina foi submetida. Cada disciplina corresponde a uma classe, ou seja, cada disciplina é contabilizada como século XX ou século XX-XXI, por exemplo. Não há ementa classificada em duas ou mais classes de tempo. Agora acompanhe esse exemplo: 1) se o número total de disciplinas designadas como história da "América" é 109 e 26 delas são classificadas como tempo presente -11 (metade das 22 destinadas ao período XIX-XX) + 11 (século XX) + 4 (séculos XX e XXI) $=26$ - temos então o valor relativo do tempo presente dentro do grupo de disciplinas história da "América", que é, aproximadamente, 24\%; 2) quando relacionamos o número total de horas $(6.658 \mathrm{~h})$ prescritas para as disciplinas de história da América (109) com a carga horária total (42.462h) de todas as disciplinas (674) de todos os cursos examinados que apresentam ementas (44), temos o valor relativo do grupo história da América no conjunto dos cursos, que é de $\mathbf{1 5 , 7 \%}$ da referida carga horária; 3) quando, por fim, relacionamos o espaço ocupado pelo tempo presente no conjunto de disciplinas de história da América (24\%) com o espaço ocupado pelo conjunto de disciplinas de história da América na carga horária de todas as disciplinas de todos os cursos disponibilizada por todas as instituições (15,7\%), concluímos que o tempo presente (séculos XX-XXI), dentro das disciplinas de história da América, representa, efetivos e finais 3,7\% da oferta de saberes a ensinar no Brasil, limitados, evidentemente, à referida amostra.
} 


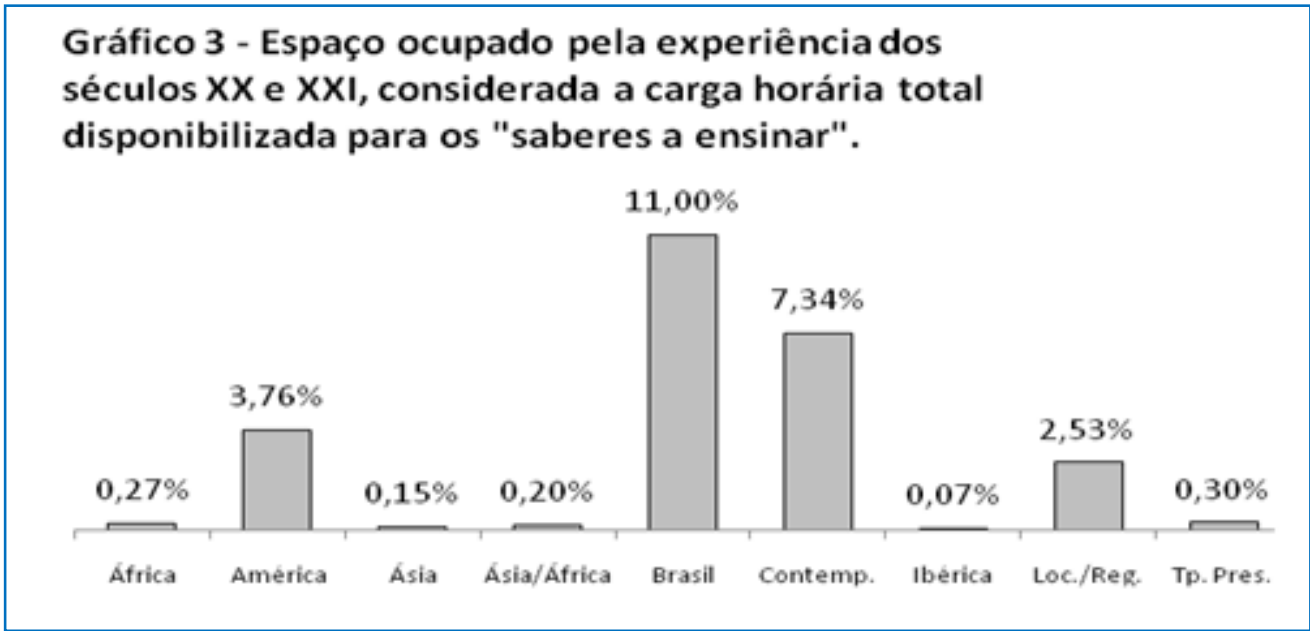

\section{Gráfico 4 - Espaço ocupado pelos períodos clássicos no ensino de história no Brasil, considerada a quantidade de disciplinas relativas aos "saberes a ensinar".}

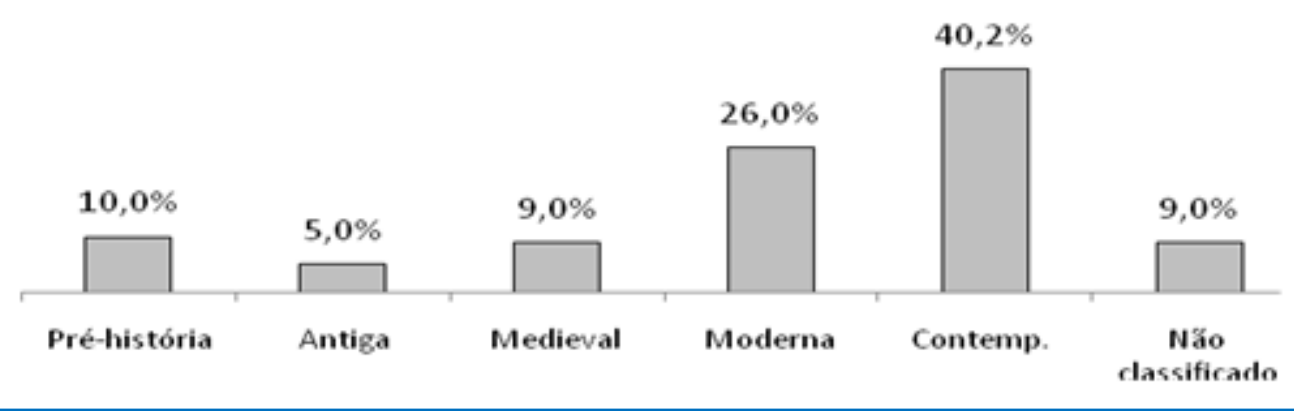

Com esses números, podemos, enfim, concluir: os séculos XX e XXI preenchem, aproximadamente, $25 \%$ da carga horária total, enquanto os demais $75 \%$ são distribuídos entre os clássicos períodos históricos em vigor no Brasil: pré-história (10\%), antiga (5\%), medieval (9\%), moderna (26\%), contemporânea centrada no século XIX (15\%) e contemporânea e tempo presente centradas nos séculos XX e XXI (25,3\%) (Gráfico 4).

Evidentemente, consideramos os dados relativos ao currículo prescrito, e uma análise sobre o currículo praticado pode indicar resultado bem diferente (para mais ou para menos). Contudo, é ainda possível interrogar: será que podemos dizer que as novas abordagens, objetos e problemas que temos importado nos últimos 30 anos teriam provocado algum abalo no tão criticado quadripartidarismo "francês"? Fica a questão em aberto, porque agora vamos tratar da natureza desse tempo presente que ocupa $1 / 4$ do número de disciplinas classificadas como "saberes a ensinar". 


\section{Brasil ou mundo? Acontecimento ou estrutura?}

Para responder à questão desse título, é importante, novamente, deixá-los cientes das limitações e fragilidades das fontes. As ementas, como nós professores sabemos, são indicadores de conteúdos, isto é, constituem o currículo prescrito, e não, obviamente, o praticado ou avaliado nos cursos de história. O outro problema é a forma de apresentação do conteúdo. Nem todos os colegas primam pela clareza no momento de construí-la, à exemplo do que orientam os autores especializados na elaboração de objetivos educacionais. O velho Halph Tyler é um bom exemplo desse tipo propedêutica. Uns entendem as ementas como aglomerados de assuntos - entre os quais os acontecimentos, ideias, personagens ou estruturas. Outros pensam as ementas como verdadeiras expectativas de aprendizagem, como entendemos que elas deveriam ser efetivamente - na ausência de metas prescritas nos programas para os alunos. Dizendo de outro modo, uma ementa clara deveria não somente anunciar substantivos, mas também envolver os verbos que, junto aos substantivos, dariam sentido aos enunciados. Observem esses exemplos e perceberão a diferença: 1. "Compreender o papel central do Estado brasileiro no processo de industrialização promovido durante o período Vargas" (UNIR); 2. "Governo Vargas e sua complexa base social e política" (UNIFESP). Qual dos dois oferece maior clareza sobre o que se espera que o aluno aprenda (ou que o professor ensine)?

A terceira limitação, como desdobramento da precedente, é a variedade de caminhos entre o anúncio sintético e o anúncio analítico percorrido pelos elaboradores de conteúdos. Essa característica (virtude ou fragilidade?) fornece o nosso primeiro elemento classificador dessa tipologia que criamos para responder à questão precedente. Seguindo tal caráter e considerando a ênfase na sintaxe - o termo isolado, o termo relacional, o termo que vem ao início ou ao fim da frase -, encontramos cinco classes de conteúdo: 1. Acontecimento(s) isolado(s) - "Primeira Grande Guerra" (UFES); 2. A experiência humana em caráter unidimensional - "Experiências sociais nos seringais acreanos" (UFAC), 3. A experiência humana em caráter multidimensional “Transformações e projeções de ordem econômica, política, social e cultural do Estado de Alagoas, do século XIX à contemporaneidade" (UFAL); 4. Acontecimento(s) explorado(s) em uma dimensão - a política, por exemplo, "República Nova: tempo do nacional- 
estatismo" (UFPEL); 5. Acontecimento(s) explorado(s) em várias dimensões - "O golpe militar de 1964, seus significados socioeconômicos e desdobramentos político-culturais" (UFAC).

Tabela 2 - Distribuição relativa dos itens de ementa segundo o conteúdo abordado e as escalas nas quais se expressam ${ }^{20}$.

\begin{tabular}{|l|c|c|c|c|c|}
\hline Conteúdos Substantivos & Nacional & Extra* & Local & NC** & Total \\
\hline Acontecimento & $25 \%$ & $41 \%$ & $19 \%$ & $11 \%$ & $27 \%$ \\
\hline Multidimensional & $16 \%$ & $13 \%$ & $17 \%$ & $44 \%$ & $12 \%$ \\
\hline Multidimensional/acontecimento & $4 \%$ & $1 \%$ & $1 \%$ & $0 \%$ & $2 \%$ \\
\hline Unidimensional & $19 \%$ & $17 \%$ & $17 \%$ & $11 \%$ & $15 \%$ \\
\hline Unidimensional/acontecimento & $8 \%$ & $5 \%$ & $0 \%$ & $11 \%$ & $22 \%$ \\
\hline Não classificado & $28 \%$ & $23 \%$ & $47 \%$ & $22 \%$ & $22 \%$ \\
\hline TOTAL & $100 \%$ & $100 \%$ & $100 \%$ & $100 \%$ & $100 \%$ \\
\hline
\end{tabular}

(*) Extranacional. (**) Não classificado.

Fonte: Produzido pelo autor a partir dos projetos pedagógicos dos cursos de graduação.

Examinando atentamente os números relativos à quantidade de itens de ementa, dispostos na última coluna (“Total”) da Tabela 2, podemos facilmente perceber o equilíbrio entre a experiência unidimensional (27\%) e os acontecimentos apresentados isoladamente (27\%) e o reduzido espaço para a experiência multidimensional (14\%). Quando avaliada a presença dos referidos acontecimentos e dimensões nas instituições, percebemos que o unidimensional é majoritário, estando presente em $46 \%$ das instituições, enquanto os itens de ementa multidimensionais constam em $24 \%$ dos projetos pedagógicos. O equilíbrio - multi/uni - predomina em 15\% das instituições ${ }^{21}$. Como os acontecimentos serão explorados no próximo tópico, conheçamos um pouco mais sobre os sentidos da multi e da unidimensionalidade nas abordagens prescritas como o tempo presente.

\footnotetext{
${ }^{20}$ A tabela não mostra, mas é importante considerar que, no total de itens de conteúdo, as ementas variam de 2 a 70 itens, com média de 27.

${ }^{21}$ Para um total de 41 instituições analisadas, ou seja, que contemplam itens de ementas que exploram as dimensões uni e multi.
} 
Pela Tabela 2, percebemos que, na experiência do nacional, o aspecto unidimensional é superior. Cerca de $27 \%$ deles $^{22}$ abordam, por exemplo, a experiência do cultural em seus mais diversos sentidos - "Literatura entre tradição e Vanguarda" na América (UFPA), "Artes e culturas contemporâneas" no Brasil (UFAL) - ou a experiência do político - "Populismo na América Latina” (UFES), "Autoritarismo no Brasil República” (PUCAMP) - ou do social - "Sociedade brasileira da Proclamação da República até primeira metade do século XX” (UFSC), “Experiências sociais nos seringais acreanos (UFAC) - ou do econômico - "Industrialização na América Latina” (UFRJ) e "transformações macroeconômicas do mundo capitalista a partir da década de 1940" (UNIFESP).

Quanto à experiência unidimensional extranacional (22\%), também a cultura, economia, política e sociedade são exploradas separadamente, como nos respectivos exemplos: "Literatura entre tradição e vanguarda (UFPA) e "Culturas e identidades nas Américas dos séculos XX-XXI”; “Diferentes interpretações a respeito do desenvolvimento das nações americanas" (UFMT) e "transformações macroeconômicas do mundo capitalista a partir da década de 1940" (UNIFESP); “Formação das nações e seus dilemas” (UFAC) e "Oligarquias e populismos nas Repúblicas latino-americanas" (UNIFAC); e, por fim, o social, "Transformações da sociedade norte-americana e relações do país com a América Latina” e "Desenvolvimentos e desigualdades nas sociedades latino-americanas dos séculos XX-XXI" (UNIFAP).

O mesmo podemos afirmar sobre a experiência local, que reserva 17\% dos seus itens de ementa para narrar, isoladamente, as "Novas identidades culturais [em Santa Catarina]" (UDESC), a "economia do sul do Mato Grosso no final do século XX (UEMS) ou “A Paraíba no sistema oligárquico” (UFCG).

Quanto à experiência multidimensional, a Tabela 3 depõe sobre as variedades de composição empregadas pelas instituições, além de deixar mais clara a distribuição dos itens unidimensionais de ementa (nacional, transnacional e local), exemplificados nos parágrafos anteriores. É possível perceber que as combinações envolvem mais a

\footnotetext{
${ }^{22}$ Relembramos que a ordem de grandeza está relacionada à quantidade de itens de ementa (tópicos ou sentenças que veiculam conteúdo). Nesse caso, $27 \%$ são a soma dos $19 \%$ (unidimensional) e $8 \%$ unidimencional/acontecimento).
} 
experiência do econômico, ou seja, a acumulação de riqueza - não exatamente na sequência apresentada em cada registro - permanece elemento importante para os elaboradores de currículo e condição explicadora dos acontecimentos.

Tabela 3 - Frequência das dimensões da experiência humana representada pelos itens de ementas, considerando o número total de instituições analisadas.

\begin{tabular}{|l|c|c|c|c|c|}
\hline Escala & Econômico & Social & Político & Cultural & Outros \\
\hline Nacional & $28 \%$ & $44 \%$ & $81 \%$ & $28 \%$ & $0 \%$ \\
\hline Extranacional & $59 \%$ & $44 \%$ & $72 \%$ & $22 \%$ & $0 \%$ \\
\hline Local & $50 \%$ & $21 \%$ & $62 \%$ & $26 \%$ & $0 \%$ \\
\hline
\end{tabular}

Fonte: Produzido pelo autor a partir dos projetos pedagógicos dos cursos de graduação.

Outra constatação é a aparição, ainda que rara, das novas dimensões, recentemente introduzidas na historiografia, como o nível científico-tecnológico - que já se desprende da ampliada ideia de "cultura" - e as questões "ambientais", vistas não somente como efeito de um sistema econômico perverso.

Por fim, os dados também sugerem que a combinação economia-política aparece equilibrada entre o nacional e o transnacional, enquanto o clássico conjunto economia/sociedade/política/cultura, em termos transnacionais, é duas vezes mais frequente nas instituições, no que diz respeito à experiência nacional.

Há, porém, uma última forma de ler a quantidade de itens de ementas e a sua relativa presença nos projetos pedagógicos das instituições. Não obstante as várias combinações apresentadas na Tabela 3, quando separados cada um dos níveis aqui citados, isto é, quando escandido um item de ementa - como evolução "Política, econômica, social e cultural do século XX no Espírito Santo" (UFES) - em "política”, “economia”, "sociedade” e “cultura”, percebemos que a distribuição dos níveis de experiência ganha outro sentido.

Aqui, independentemente da quantidade de itens, o que aferimos são as escolhas puramente em termos de dimensão da experiência humana. O que fica claro é a primazia do político nas três escalas referidas: nacional (81\% das instituições), extranacional (72\%) e local (62\%). Além disso, e já respondendo à questão do título desse tópico, independentemente das várias combinações experimentadas, o acontecimento - no 
clássico sentido de evento de breve duração - reina sobre a estrutura quando o conteúdo é a história dos séculos XX e XXI.

\section{A vulgata acontecimental extranacional}

Quando analisado caso a caso, a supremacia do extranacional (48\%) é confirmada. Em 63\% das instituições, o número de itens de conteúdo constituídos por acontecimentos isolados extranacionais é superior aos acontecimentos isolados nacionais. Em seis delas, os extranacionais constituem $100 \%$ do total de itens. Quais substantivos, então, realizam essa vulgata? Os substantivos mais frequentes nas ementas ${ }^{23}$ são descritos na Tabela 4, que também indica os números relativos ao total das instituições que apresentaram acontecimentos extranacionais.

O “Imperialismo" (53\%) é categoria elástica nas ementas. Surge como fenômeno de breve duração (1890-1918), baseado na Europa e que se espalha pelo mundo. A maior frequência, entretanto, é o “Imperialismo" que tem efeitos na África, América Latina, Ásia, capitaneado - sobretudo pelos Estados Unidos, Inglaterra e Rússia, predominante no período 1890-1989.

Tabela 4 - Acontecimentos de caráter extranacional distribuídos segundo a presença relativa no total das instituições examinadas.

\begin{tabular}{|l|c|}
\hline Descolonização/Independência & $60 \%$ \\
\hline Autoritarismo/Totalitarismo & $55 \%$ \\
\hline Imperialismo & $53 \%$ \\
\hline I Guerra Mundial & $50 \%$ \\
\hline II Guerra Mundial & $50 \%$ \\
\hline Socialismo & $50 \%$ \\
\hline Revoluções & $48 \%$ \\
\hline Guerra Fria & $45 \%$ \\
\hline Capitalismo & $40 \%$ \\
\hline Globalização & $30 \%$ \\
\hline Movimentos sociais & $30 \%$ \\
\hline
\end{tabular}

Fonte: Produzido pelo autor a partir dos projetos pedagógicos dos cursos de graduação.

23 Considerado o mínimo de presença em 30\% das 40 instituições que apresentaram acontecimentos extranacionais. 
por três referências temporais: uma extensa, que percorre todo o século $X X$, outra mais restrita, dos anos 1945 ou 1960 até o início do século XXI e, por fim, a mais rara, a década de 1930, marcada pelo Crash de 1929 e a "Grande Depressão". Evidentemente, podemos agregar ao "Capitalismo" a rubrica da "Globalização" (30\%)24. Isoladamente, no entanto, a atenção dos programas se divide entre os impactos da Globalização no mundo e na América Latina, datados, principalmente entre os marcos: 1990 e 2010, aproximadamente.

"I Guerra Mundial" (50\%) e "Il Guerra Mundial" (50\%) compõem a vulgata extranacional com mínimas diferenças. O primeiro acontecimento vem acompanhado de alguma ação indiciária - "emergência”, "dinâmica”, “conflitos” e "crise”. É tratada em suas causas eficientes, daí a periodização iniciar-se, em alguns casos, na última década do século XIX. Sua abrangência espacial concede espaço para a Rússia, Itália e Alemanha. O segundo acontecimento faz referências à América, Ásia, África e Oriente Médio e raramente expande os limites temporais para além do 1945 ou aquém do 1934. Apenas quatro iniciativas apresentam as duas guerras como um só acontecimento "Guerras Mundiais".

Entre uma e outra Guerra, são referidos o "Totalitarismo" e o "Autoritarismo" que, para maior clareza e representatividade - o mesmo fenômeno é classificado como totalitarismo em um e autoritarismo em outro programa -, resolvemos reuni-los. Metade dos itens explora a construção de regimes "totalitários" ou "autoritários" entre 1918 e 1945, com destaque para a Espanha, Portugal, Alemanha e Itália. A outra metade enfatiza os regimes autoritários na América Latina, ocorridos entre 1945 e o início do século XXI. Também, no mesmo intervalo, são comuns as referências a "Revoluções" na América, Ásia, América Latina (entre as décadas de 1950 e 1970), com menções esporádicas às revoluções mexicana (1910-1913) e cubana (1959) e amplo destaque para a "Revolução Russa" (1917).

\footnotetext{
24 Eles estão separados na Tabela 4 porque resolvemos dar voz às ementas, transcrevendo o que efetivamente apresentam para os alunos.
} 

impactos na América Latina. Seu estudo é guiado pelo interesse no "cenário", "questão", "apogeu” e "fim" da Guerra Fria, majoritariamente entre 1945 e o início da década de 1990.

O acontecimento "Descolonização", frequentemente aparece combinado aos termos "nacionalismo" e "independências". Os três sugerem o estudo das "relações", “conflitos”, “desenvolvimento”, “processo”, “nascimento”, “formação, “visão” e “ideias" de nacionalismo na África (1/2) , sendo metade dos itens divididos entre "África e Ásia" (1/4) e "mundo" (1/4).

Quanto ao "socialismo", ele foi desmembrado da "Revolução Russa" exatamente por se tratar de "experiência”, “evolução”, “expansão”, “crise”, “desmantelamento”, "desmanche", "queda", “colapso" e "fim". Em outras palavras, a referência ao "socialismo" ou aos "socialismos" indica a difusão da "ideologia”, do "sistema econômico" ou “político" pelo mundo, sobretudo no pós-Revolução Russa de 1917 e no pós-II Guerra Mundial. Metade das menções, todavia, refere-se ao fim do "socialismo real” na “União Soviética” e no “Leste Europeu”, datado entre 1989 e 1992.

A rubrica "movimentos sociais" reúne inícios, "fins" e "questões" relacionadas à organização de "trabalhadores”, “operários”, “camponeses”, “estudantes”, “pacifistas”, “ambientalistas", "feministas”, dispersos ao longo do século XX, na “França”, "América Latina" e no "Mundo" (1/2).

Cabe registrar, por fim, que, de todos os acontecimentos residuais “anticomunismo”, “formação da cidadania”, "conflitos étnicos”, "expansão da cultura norte-americana", “avanço da esquerda”, “Guerra do Vietnã, “Holocausto", "Terrorismo", "Nova ordem mundial", "Pós-modernidade”, "Renascimento cultural africano" e "processo de democratização" - a rubrica "resistência" é a que mais chega próximo do grupo apresentado na Tabela 4, em termos de frequência. Ela está presente em 10 instituições, designada como "resistência” na África (1950-1980 e 1990-2010), 
“contracultura no mundo", “contra revolução" e "resistência” da América Latina em relação aos EUA (1950-1970).

\section{A vulgata do acontecimento nacional/local}

Há pouco, afirmamos que a vulgata acontecimental nacional é, significativamente, menos expressiva que o mesmo fenômeno em nível extranacional. Porém, levando em conta que os itens de experiências multi e unidemensionais também aparecem acompanhados de acontecimentos, respectivamente $2 \%$ e $22 \%$ (Tabela 2), 0 acontecimento acaba por representar a mesma importância nas duas instâncias (nacional e extranacional). Para tirar melhor proveito dos dados, rebaixamos o ponto de corte para 1/4, ou seja, construímos a Tabela 5 com acontecimentos flagrados em, no mínimo, $25 \%$ dos 37 projetos pedagógicos (e instituições) que possibilitaram esse tipo de levantamento. 0 resultado foi o seguinte:

Tabela 5 - Acontecimentos de caráter nacional distribuídos segundo a presença relativa no total das instituições examinadas.

\begin{tabular}{|l|l|}
\hline Primeira República & $68 \%$ \\
\hline Ditadura Militar & $57 \%$ \\
\hline Movimentos sociais & $46 \%$ \\
\hline Revolução de 1930 & $35 \%$ \\
\hline Democratização & $35 \%$ \\
\hline Estado Novo & $30 \%$ \\
\hline Golpe de 1964 & $30 \%$ \\
\hline Movimento operário & $24 \%$ \\
\hline
\end{tabular}

Fonte: Produzido pelo autor a partir dos projetos pedagógicos dos cursos de graduação.

Vamos inverter a ordem de frequência para oferecer melhor inteligibilidade ao conjunto. Observem que a Primeira República (68\%) - também referida como "República Velha”, "República burguesa" e "Novo regime" - está presente em mais da metade das ementas. Dela, são estudados o “nascimento, “processo", a “consolidação", 
“construção", “estrutura”, “formação”, e também, o “projeto”, a “ideia” e a "historiografia".

A herança da "Primeira República" também aparece no item "Revolução de 1930" (35\%) - “mudança”, “compreensão”, “formação" e "historiografia” - e no "movimento operário" (24\%), marcadamente registrado como fenômeno do período 1900-1930, com rara extensão até o ano de 1964.

A “emergência” e a "organização" do “Estado Novo" (30\%) também não estão obrigatoriamente relacionadas aos dois precedentes, ou seja, as ementas, necessariamente, não incluem os três itens numa mesma disciplina e instituição. Já o “Golpe de 1964" (30\%) e a "Ditadura Militar" (57\%), quase sempre aparecem coligados, seguidos do fenômeno "Democratização" (35\%). Ditadura Militar é também referida como "governo", com o ilógico vocábulo "regime militar", além de "poder" e "Estado" autoritários. Porém, nem toda a “Democratização" refere-se ao período que se inicia em 1985 (são raras as referências a 1982 ou 1984). Duas instituições, ao menos, abordam “democratização" como acontecimento dos anos 1930-1940 e 1950-1964, respectivamente. Se considerarmos os residuais "populismo" e "nacionaldesenvolvimentismo", que abarcam as décadas de 1930 a 1960, mais cinco instituições podem compor o item.

Por fim, observemos o item de ementa que está disperso ao longo do século XX: “Movimentos sociais". A ação latente, relacionada aos movimentos sociais - "rurais", “do campo", "populares", "urbanos" e, até, "ligas camponesas" e "MST" - é a origem e a importância nas lutas contra a oligarquia, em prol das reformas de base e em apoio à expansão dos direitos sociais. Daí a sua tripartição entre 1900-1930, 1960-1980 e 19902010, aproximadamente.

Vemos, então, que a vulgata local é residual, não chegando a $5 \%$ do total de acontecimentos inventariados. Ela frequenta, evidentemente, as disciplinas de história local/regional fluminense, sergipana, indígena (UEMS), do Nordeste, Paraíba, Regional (UEMS), Rio Grande do Norte, Rio Grande do Sul, Rondônia e Santa Catarina e funcionam como caixa de ressonância da acontecimentalidade de caráter nacional e extranacional “Primeira República”, “coronelismo”, “oligarquia”, “integralismo”, “I Guerra Mundial” 
“Revolução de 1930”, “Golpe de 1964”, “abertura política” e “democratização” pós-1984. A experiência especificamente local, contudo, é raríssima; "banditismo", "Guerra da Borracha" e "Guerra do Contestado" são os exemplos marcantes.

\section{Conclusões}

Neste texto, propusemos construir e apresentar um perfil do lugar e da natureza do presente, significado operatoriamente como séculos XX e XXI, nos cursos de história de 55 instituições de nível superior, públicas e brasileiras, abrangendo todos os estados da federação. As conclusões que gostaríamos de destacar estão, obviamente, relacionadas à emergência da BNCC e da futura reforma das licenciaturas. Por isso, cumpre-nos afirmar, em primeiro lugar, que os "saberes a ensinar" ocupam 39\% da carga horária total dos currículos dos cursos de graduação no Brasil. Em média, cada instituição reserva idênticos 39\% das horas às disciplinas que correspondem, diretamente, às supostas necessidades escolares. Além disso, tentamos demonstrar também que tais disciplinas são justificadas e limitadas a partir dos recortes espacial, cronológico, espacial/cronológico e étnico-culturais.

Em segundo lugar, os dados disponíveis indicam que a experiência dos séculos XX e XXI é mais frequente nas disciplinas História do Brasil (11\% da carga horária) e História Contemporânea (7,3\%). A HTP é medianamente presente nas disciplinas História da América (3,7\%) e local/regional (2,5\%). Residuais, em termos de HTP, são as disciplinas História da África, da Ásia, Ásia-África e Ibérica.

Os dados também permitem concluir que os séculos XX e XXI preenchem $25 \%$ da carga horária total alocada nos cursos de graduação em história, no Brasil, restando 75\% para as disciplinas Pré-história (10\%), Antiga (5\%), Medieval (9\%) e Moderna (26\%). Outra constatação que os números apontam é a presença explícita do "econômico" como dimensão explicadora da experiência do tempo presente. Contudo, quando escandidos os itens de ementa, percebemos que o "político" (não necessariamente economia política) é predominante nas três escalas em análise: ele está presente em $81 \%$ das instituições quando o acontecimento é de caráter nacional e, respectivamente, em $72 \%$ e 
$62 \%$, quando os espaços são o extranacional e o local. Além disso, podemos também afirmar que o acontecimento reina sobre a estrutura.

Os últimos elementos da análise - esses, deliberadamente descritivos - também indicam que os acontecimentos de caráter nacional, mais frequentes nas instituições, são a "descolonização"|“Independência”, o "autoritarismo"|"totalitarismo", “I Guerra Mundial”, “Il Guerra Mundial”, “socialismo", “Revoluções”, com destaque para a experiência russa de 1917, a "Guerra Fria”, a experiência do “capitalismo", a "Globalização" e os “movimentos sociais". Em termos nacionais e locais, há convergência para os acontecimentos da "Primeira República”, "Ditadura militar", "movimentos sociais”, “Revolução de 1930", “democratização", "Estado Novo”, “Golpe de 1964" e “movimento operário".

Esses resultados nos estimulam a muitas conjecturas que podem contribuir para a construção de currículos de formação inicial ${ }^{25}$ um pouco mais atenciosos com as demandas do nosso presente. Comentaremos três. Em primeiro lugar, considerada a lógica superficial, infelizmente ainda dominante, de que os milênios de humanidade ainda que desigualmente documentados - devem ser simetricamente distribuídos ao longo da experiência formativa, somos agora induzidos a afirmar que o tão criticado “quadripartidarismo francês” parece estar em desprestígio no ensino superior. A crítica é intensa por parte dos críticos da BNCC de que a comissão responsável pela primeira versão do documento queria extinguir as histórias antiga e média e, dessa forma, minimizar as nossas supostas fundações em uma imaginada cultura greco-romana-cristãeuropeia, parece não ter fundamentos. É provável que um exame baseado em ampliada amostra possa evidenciar que os próprios curriculistas do ensino superior são coresponsáveis pela citada minimização das nossas "raízes".

Outra consideração importante tem a ver com a vulgata dos livros didáticos destinados aos ensinos fundamental e médio. Ao examinar a predominância do

\footnotetext{
${ }^{25}$ No sentido anunciado por J. G. Sacristán (2000, p. 107-108): “Essa política que prescreve certos mínimos e orientações curriculares tem uma importância decisiva [...] como meio de conhecer, desde uma perspectiva pedagógica, o que ocorre na realidade escolar, à medida que, neste nível de determinações, se tomam decisões e se operam mecanismos que têm consequências em outros níveis de desenvolvimento do currículo."
} 
acontecimento sobre a estrutura, da economia sobre o político, e, principalmente, do conteúdo substantivo majoritário nas ementas dos projetos pedagógicos - e, da mesma forma que a consideração anterior, se a amostra ampliada confirmar os dados aqui apresentados -, seremos inclinados a concluir que os quadros de ferro - não dos de Varnhagem, mas ao do estatismo paulista - da história recente brasileira são instituídos pelos cursos superiores de história e não pelos livros didáticos. Em outros termos, refletir sobre a determinante corrente - oligarquia, que leva ao populismo, que leva à ditadura militar, que leva à redemocratização etc. - é obra de colegiados de departamentos de história e não de autores e avaliadores envolvidos com o Programa Nacional do Livro Didático - PNLD.

Por fim, está também nas mãos dos profissionais da formação inicial - caso lhes seja interessante - a tarefa de livrar-nos das opções fatalistas fornecidas pelas ementas no que diz respeito à contribuição do conhecimento histórico para a formatação de um projeto de nação: filhos indesejados do ocidentalismo das Europas do Norte, Central e Continental ou eternas vítimas do modo de vida, do colonialismo e do industrialismo dos “EUA". São essas as dominantes mensagens que os autores dos projetos pedagógicos querem fazer incutir nas mentes dos graduandos e, consequentemente, dos escolares recém-egressos do ensino médio.

\section{Referências}

AGOSTINHO, Santo. As confissões. Trad. Frederico Ozanam Pessoa de Barros. São Paulo: Edameris, 1964.

ARÓSTEGUI, Julio. La historia vivida: sobre la historia del presente. Madrid: Alianza, 2004.

BERETA, Cristiane. Escrever a história do tempo presente: algumas questões e possibilidades. Tempos Históricos, Marechal Cândido Rondon, v.9, p.257-276, 2006. 
BERNECKER, Walther. La investigación histórica del "tiempo presente” em Alemania. Cuadernos de Historia Contemporánea, Madrid, n. 20, p. 83-98, 1998.

BEVERNAGE, Berber; LORENZ, Chriz. Breaking up time - negotiating the borders between present, past and future. Storia della Storiografia, v. 63, n. 1, p. 31-50, 2013.

BORGES, Viviane Trindade. Carandiru: os usos da memória de um massacre Viviane Trindade. Revista Tempo e Argumento, Florianópolis, v. 8, n. 19, p. 04-33. set./dez. 2016.

BRASIL. Presidência da República. Lei n. 13.005, de 25 de junho de 2014. Plano Nacional de Educação - PNE. Disponível em: http://www.planalto.gov.br/ccivil_03/_ato20112014/2014/lei/l13005.htm. Capturado em 21 jul. 2017.

BRAUDEL, Ferdnand. Gramática das Civilizações. 3ed. São Paulo: Martins Fontes, 2004.

CAIMI, F. E. A Licenciatura em História frente às atuais políticas públicas de formação de professores: um olhar sobre as diefinições curriculares. Revista Latino-Americana de História. v.2, n.6, p. 193-209, 2013.

CARBONELL, Charles-Olivier. Histoire et historiens: une mutation idéologique des historiens français 1865-1885. Toulouse: Privat, 1976.

CHAMBERS, Vanessa. The teaching and assessment of contemporary history in UK higher education institutions. HE Academy Subject Centre for History, Classics and Archeology. Londres, mar. p. 1-10, 2008.

CHAVEAU, Agnès; TÉTARD, Philippe. Questões para a história do presente. Bauru: Edusc, 1999.

DOSSE, François. Entrevista. História Agora, n. 7, mar. 2007. (Entrevista concedida a Ana Carolina Fiuza F.). Disponível em: <http://www.historiagora.com/revistasanteriores/historia-agora-no7/39/118-entrevista-com-francois-dosse>. Acesso em: 3 jan. 2014.

GUIBERT, Pascal; TROGER, Vicent. Peut-on encore former des enseignants? Paris: Armand Colin, 2012.

GUIRAUD, Paul. Problèmes et methods de la statistique linguistique. Paris: ReidelPUF,1960.

HARTOG, François. Entrevista. História da historiografia. Ouro Preto, n.10, p. 351-371, dez. 2012. (Entrevista concedida a Henrique Estrada Rodrigues e Fernando Nicolazzi). 
INGELBACH, Gabriele. Klio macht Karriere. Die Institutionalisierung der Geschichtswissenschaft in Frankreich und den USA in der zweiten Hälfte des 19. Jahrhunderts. Göttingen: Vandenhoeck \& Ruprecht, 2003.

\section{INSTITUTO FEDERAL DE EDUCAÇÃO CIÊNCIA E TECNOLOGIA DE GOIÁS. [Curso de} Licenciatura em História. Goiás: IFG, 2010.

KOSELLECK, Reinhart. Futuro passado. Contribuição à semântica dos tempos históricos. Rio de Janeiro: Contraponto: Ed. PUC-Rio, 2006.

MARTINS, Estevão de Rezende. História e teoria na era dos extremos. Fenix - Revista de História e Estudos Culturais. v. 3, n. 2, p. 1-19, 2006.

PALMOWSKI, Jan; READMAN, Kristina Spohr. Speaking truth to power: contemporary history in the twenty-first century. Journal of Contemporary History, v. 46, n. 3, p. 485-55, 2011. Disponível em: http://jch.sagepub.com/content/46/3/485.citation. Acesso em: 28 fev. 2014.

PONTIFÍCIA UNIVERSIDADE CATÓLICA DE CAMPINAS. [História Licenciatura]. Campinas: PUC-CAMPINAS, [sd.].

PONTIFÍCIA UNIVERSIDADE CATÓLICA DO RIO DE JANEIRO. [Licenciatura em História/Bacharelado em História]. Rio de Janeiro: PUC-RJ, [sd.].

PONTIFÍCIA UNIVERSIDADE CATÓLICA DO RIO GRANDE DO SUL. [Curso de História: ementas das disciplinas]. Porto Alegre: PUC-RS, 2011.

PÔRTO JÚNIOR, Gilson. História do tempo presente. Bauru: Edusc, 2007.

RIBEIRO, A. Entre as práticas e teorias e vice-versa. A prática de ensino como componente curricular nas licenciaturas em história no Brasil após 2002. Ponta Grossa, 2015. Tese (Doutorado em Educação) - Programa de Pós-Graduação em Educação, Universidade Estadual de Ponta Grossa.

RODRIGUES, José Honório. Periodização. In: Teoria da História do Brasil: introdução metodológica. 3 ed. São Paulo: Companhia Editora Nacional, 1969. p. 112-124.

ROUSSO, Henry. La dernière catástrophe: I'histoire, le présent, le contemporain. Paris: Galimard, 2012.

ROUSSO, Henry. The last catastrophe. The writing of contemporary history. Cadernos do Tempo Presente, São Cristóvão, v. 11, mar. 2013. Disponível em: 
<http://www.getempo.org/index.php/revistas/56-n-11-marco-de-2013/artigos/169-1-thelast-catastrophe-the-writing-of-contemporary-history>. Acesso em: 3 jan. 2014.

RÜHS, F. G. Entwurf einer Propädeutik des historischen Studiums. Berlim: Hans schleier, 1811.

RÜSEN, Jörn. Conceitos históricos. In: Reconstrução do passado: teoria da história II - oS princípios da pesquisa histórica. Brasília: Editora da UnB, 2007. p. 91-100.

SACRISTÁN, J. Gimeno. $O$ currículo: uma reflexão sobre a prática. 3 ed. Porto Alegre: Atmed, 2000.

SILVA, Francisco Carlos Teixeira da. Vox, voces - (re)memorar. Rio de Janeiro: Multifoco, 2012.

UNIVERSIDADE DE BRASÍLIA. [Curso de Graduação em História - Licenciatura e Bacharelado]. Brasília: UnB, [sd.]. Disponível

em:<http://www.his.unb.br/index.php/pt/perfil-do-curos> . Acesso em: 12 fev. 2014.

UNIVERSIDADE DO ESTADO DO RIO DE JANEIRO. História (Licenciatura). Rio de Janeiro [sd.].

UNIVERSIDADE DO ESTADO DO RIO GRANDE DO NORTE. Projeto Pedagógico do Curso de Licenciatura em História (Campus Central - Mossoró). Mossoró: UERN, 2013.

UNIVERSIDADE ESTADUAL DE ALGOAS. Projeto Político e Pedagógico dos Cursos de Licenciatura Plena em História. Arapiraca: UNEAL, 2004.

UNIVERSIDADE ESTADUAL DE CAMPINAS. Projeto Pedagógico - Curso de Graduação em História. Campinas: Unicamp, 2014.

UNIVERSIDADE ESTADUAL DE MATO GROSSO DO SUL. História Licenciatura. [Amambaí]: UEMS, 2007.

UNIVERSIDADE ESTADUAL DE SANTA CATARINA. Curso de História. Florianópolis: UDESC, 2007.

UNIVERSIDADE ESTADUAL DE SANTA CRUZ. [Estrutura Curricular]. Ilhéus: UESC, 2006.

UNIVERSIDADE ESTADUAL DE SÃO PAULO. Programas das Disciplinas do Bacharelado em História da USP (2013/02). São Paulo: USP, [sd.]. Disponível em:

<http://historia.fflch.usp.br/node/1349> Acesso em: 24 fev. 2014. 
UNIVERSIDADE ESTADUAL DO OESTE DO PARÁ. [Licenciatura Plena em História]. Santarém: UFOPA, 2010.

UNIVERSIDADE FEDERAL DA FRONTEIRA SUL. Projeto Pedagógico do Curso de Graduação em História - Licenciatura. Chapecó: UFFS, 2010.

UNIVERSIDADE FEDERAL DE ALAGOAS. Projeto Pedagógico do Curso de Licenciatura Plena em História. Maceió: UFAL, 2006.

UNIVERSIDADE FEDERAL DE ALAGOAS. Projeto Político Pedagógico do Curso de História-Licenciatura (Campus do Sertão). Maeió: UFAL, 2011.

UNIVERSIDADE FEDERAL DE ALFENAS. Projeto Pedagógico do Curso de HistóriaLicenciatura. Alfenas: UNIFAL, 2011.

UNIVERSIDADE FEDERAL DE GOIÁS. Currículo Pleno do Curso de Graduação em História - modalidade licenciatura, para os alunos do Campus de Goiânia. Goiânia: UFG, 2004.

UNIVERSIDADE FEDERAL DE JUÍZ DE FORA. Projeto Pedagógico do Curso de História. Juíz de Fora: UFJF, 2013.

UNIVERSIDADE FEDERAL DE MINAS GERAIS. Projeto Pedagógico do Curso de Graduação em História (Licenciatura e Bacharelado). Belo Horizonte, 2009.

UNIVERSIDADE FEDERAL DE OUTRO PRETO. Curso de História. [sd.]. Disponível em: http://www.prograd.ufop.br/index.php/cursos. Acesso em: 12 fev. 2014.

UNIVERSIDADE FEDERAL DE PELOTAS. [Projeto Pedagógico do Curso de História]. Pelotas: UFPEL, 2010.

UNIVERSIDADE FEDERAL DE PERNAMBUCO. [Projeto Pedagógico do Curso de História). Recife: UFPE, 2013.

UNIVERSIDADE FEDERAL DE RONDÔNIA. Projeto Político Pedagógico do Curso de Licenciatura em História. Boa Vista, 2012.

UNIVERSIDADE FEDERAL DE SANTA CATARINA. Projeto Político Pedagógico do Curso de Graduação em História - Habilitação única (Bacharelado e Licenciatura). Florianópolis, UFSC, 2006.

UNIVERSIDADE FEDERAL DE SANTA MARIA. [Disciplinas pertencentes ao currículo]. Santa Maria: UFSM, 2004. 
UNIVERSIDADE FEDERAL DE SÃo JOÃO DEL REI. Projeto Político Pedagógico do Curso de Graduação em História. São João del Rei: UFSJR, 2003.

UNIVERSIDADE FEDERAL DE SÃO PAULO (CAMPUS GUARULHOS). Projeto Pedagógico do Curso de História (Bacharelado/Licenciatura). São Paulo: UNIFESP, 2010.

UNIVERSIDADE FEDERAL DE SERGIPE. Curso de Graduação em História Licenciatura. São Cristóvão, 2011.

UNIVERSIDADE FEDERAL DE UBERLÂNDIA. Projeto Pedagógico do Curso de Graduação em História. Uberlândia: UFU, 2005.

UNIVERSIDADE FEDERAL DO ACRE. Curso de História. Rio Branco [sd.]. Disponível em: <http://200.129.173.3:2080/ementario/curriculo.action?v=194>. Acesso em: 12 fev. 2014.

UNIVERSIDADE FEDERAL DO AMAPÁ. Projeto Político Pedagógico do Curso de História Licenciatura. Macapá: UNIFAP, 2007.

UNIVERSIDADE FEDERAL DO AMAZONAS. Curso de Licenciatura Plena em História: Projeto Pedagógico. Manaus: UFAM, 2006.

UNIVERSIDADE FEDERAL DO CEARÁ. Projeto Político Pedagógico do Curso de História Modalidade Licenciatura. Fortaleza: UFC, 2005.

UNIVERSIDADE FEDERAL DO ESPÍRITO SANTO. Projeto Pedagógico do Curso de História: habilitação em licenciatura/habilitação em bacharelado (versão 2006). Vitória: UFES, 2008.

UNIVERSIDADE FEDERAL DO MARANHÃO. Projeto Político Pedagógico de segunda licenciatura modalidade presencial para professores em exercício na educação básica pública - PARFOR (Curso História Licenciatura). São Luis: UFMA, 2010.

UNIVERSIDADE FEDERAL DO MATO GROSSO. Projeto Pedagógico do curso de História, licenciatura, modalidade presencial, do Instituto de Ciências Humanas e Sociais, do Campus Universitário de Rondonópolis. Cuiabá: UFMT, 2011.

UNIVERSIDADE FEDERAL DO PARÁ. Projeto Político Pedagógico - Licenciatura em História. Belém, 2011.

UNIVERSIDADE FEDERAL DO PARANÁ. Projeto Pedagógico da Formação Acadêmica e Profissional a ser oferecida aos Alunos do Curso de Graduação em História da UFPR.

Curitiba: UFPR, 2011. 
UNIVERSIDADE FEDERAL DO PIAUÍ. Projeto Político-Pedagógico Curso de Graduação, Licenciatura em História Diurno e Noturno. Terezina: UFPI, 2011.

UNIVERSIDADE FEDERAL DO RECÔNCAVO BAIANO. Curso de História - Licenciatura (Campus de Cachoeira). Cachoeira: UFRB, 2006. Disponível em: < http://www.ufrb.edu.br/cahl/index.php/cursos/historia>. Acesso em 12 fev. 2014.

UNIVERSIDADE FEDERAL DO RIO DE JANEIRO. Curso de Graduação em História (Bacharelado e Licenciatura). Rio de Janeiro: UFRJ, [2014]. Disponível em: <http://www.pr1.ufrj.br/index.php/cursos-de-graduao-mainmenu-124/163-cursos/h/136histria>. Acesso em 12 fev. 2014.

UNIVERSIDADE FEDERAL DO RIO GRANDE DO NORTE. Projeto Político-Pedagógico do Curso de História (Seridó). Natal: UFRN, 2005.

UNIVERSIDADE FEDERAL DO RIO GRANDE DO SUL. Projeto Pedagógico do Curso de História. [Porto Alegre]: UFRGS, [2004].

UNIVERSIDADE FEDERAL DO TOCANTINS. Projeto Pedagógico do Curso de História Licenciatura (Campus de Araguaína). Palmas: UFT, 2009.

UNIVERSIDADE FEDERAL DO TOCANTINS. Projeto Pedagógico do Curso de História Licenciatura (Campus de Porto Nacional). Palmas: UFT, 2011.

UNIVERSIDADE FEDERAL DO TRIÂNGULO MINEIRO. Projeto Pedagógico do Curso de Graduação em História - Licenciatura. Uberaba: UFTM, 2010.

UNIVERSIDADE FEDERAL RURAL DO RIO DE JANEIRO. Grade Curricular do Curso de Licenciatura em História Noturno. Nova Iguaçu: UFRRJ, [sd.].

UNIVERSIDADE FEDRAL DE CAMPINA GRANDE. Projeto Pedagógico do Curso de Licenciatura em História. Cajazeiras: UFCG, 2007.

UNIVERSIDADE REGIONAL DO CARIRI. Projeto Político-Pedagógico do Curso de História. Crato: URCA, 2004.

UNIVERSIDAE FEDERAL DOS VALES DO JEQUITINHONHA E MUCURI. Projeto Pedagógico do Curso de Licenciatura em História. Diamantina: UFVJM, 2011.

UNIVRSIDADE FEDERAL DE RONDÔNIA. Projeto Político Pedagógico do Curso de Licenciatura Plena em História. Rolim de Moura: UNIR, 2008. 
VARELLA, Flávia et al. Tempo presente e usos do passado. Rio de Janeiro: FGV, 2012. 